\title{
Deficit of Striatal Parvalbumin-Reactive GABAergic Interneurons and Decreased Basal Ganglia Output in a Genetic Rodent Model of Idiopathic Paroxysmal Dystonia
}

\author{
Manuela Gernert, Melanie Hamann, Mustapha Bennay, Wolfgang Löscher, and Angelika Richter \\ Department of Pharmacology, Toxicology, and Pharmacy, School of Veterinary Medicine, Hannover, \\ 30559 Hannover, Germany
}

\begin{abstract}
The underlying mechanisms of various types of hereditary dystonia, a common movement disorder, are still unknown. Recent findings in a genetic model of a type of paroxysmal dystonia, the $d t^{s z}$ mutant hamster, pointed to striatal dysfunctions. In the present study, immunhistochemical experiments demonstrated a marked decrease in the number and density of parvalbuminimmunoreactive GABAergic interneurons in all striatal subregions of mutant hamsters. To examine the functional relevance of the reduction of these inhibitory interneurons, the effects of the $\mathrm{GABA}_{\mathrm{A}}$ receptor agonist muscimol on severity of dystonia were examined after microinjections into the striatum and after systemic administrations. Muscimol improved the dystonic syndrome after striatal injections to a similar extent as after systemic treatment, supporting the importance of the deficiency of striatal GABAergic interneurons for the occurrence of the motor disturbances. The disinhibition of striatal GABAergic projection neu-
\end{abstract}

Dystonia is a common neurological syndrome characterized by involuntary, sustained contractions of opposing muscles, frequently causing twisting movements or abnormal postures (Fahn et al., 1998). Dystonia occurs as either an idiopathic (primary) disease in which no lesions within the CNS can be detected by standard techniques (approximately two-thirds of cases) or a symptom of an underlying disorder, often associated with lesions in the basal ganglia, particularly in the striatum (caudate, putamen) and thalamus (Bhatia and Marsden, 1994). Apart from dopa-responsive dystonias, the brain abnormalities responsible for idiopathic dystonias are unknown, which hampers the development of rational and effective drug treatments (McGeer and McGeer, 1995). Dystonia is regarded as a basal ganglia disorder, but the existence of various phenotypic and genotypic subtypes suggest that the pathogenesis of idiopathic dystonias is heterogeneous (Spinella and Sheridan, 1994). Otherwise, different types of dystonia in humans possibly share common neural mechanisms that can be detected by using suitable animal models, such as the $d t^{s z}$ mutant hamster (Spinella and Sheridan, 1994; Richter and Löscher, 1998).

Animal models for different types of dystonia are rare, but the $d t^{s z}$ mutant hamster shows all clinical and pharmacological characteristics of a type of hereditary dyskinesias with paroxysmal dystonia in humans (Demirkiran and Jankovic, 1995; Richter and Löscher, 1998). In this movement disorder, attacks of generalized dystonia last up to several hours and can be provoked by stress and caffeine. Medical treatment is often disappointing, but benzodiazepines have been reported to be the most effective drugs (Demirki-

\footnotetext{
Received May 2, 2000; revised June 27, 2000; accepted June 28, 2000.

This work was supported by Deutsche Forschungsgemeinschaft Grants Ge 1103/1-1 and Ri 845/1-1. We thank Dr. U. Ebert for his helpful advice on immunhistochemical analyses and C. Bartling and M. Weißing for their technical assistance.

Correspondence should be addressed to Dr. A. Richter, Department of Pharmacology, Toxicology, and Pharmacy, School of Veterinary Medicine, Bünteweg 17, Hannover, 30559 Hannover, Germany. E-mail: angelika.richter@tiho-hannover.de. Copyright (C) 2000 Society for Neuroscience $0270-6474 / 00 / 200001-07 \$ 15.00 / 0$
}

rons, as suggested by recent extracellular single-unit recordings in $d t^{s z}$ hamsters, should lead to an abnormal neuronal activity in the basal ganglia output nuclei. Indeed, a significantly decreased basal discharge rate of entopeduncular neurons was found in $d t^{s z}$ hamsters. We conclude that a deficit of striatal GABAergic interneurons leads by disinhibition of striatal GABAergic projection neurons to a reduced activity in the entopeduncular nucleus, i.e., to a decreased basal ganglia output. This finding is in line with the current hypothesis about the pathophysiology of hyperkinesias. The results indicate that striatal interneurons deserve attention in basic and clinical research of those movement disorders.

Key words: animal models; basal ganglia; GABA; dyskinesia; dystonia; electrophysiology; entopeduncular nucleus; immunohistochemistry; interneurons; movement disorders; muscimol; parvalbumin; striatum ran and Jankovic, 1995). Previous studies failed to disclose any pathomorphological alterations within the CNS in $d t^{s z}$ mutant hamsters (Wahnschaffe et al., 1990), results similar to those found in patients with idiopathic dystonias (Demirkiran and Jankovic, 1995; McGeer and McGeer, 1995). More detailed examinations confirmed an anatomically intact dopaminergic system in dystonic hamsters (Burgunder et al., 1999; Nobrega et al., 1999). Previous findings, which suggested that striatal dopaminergic overactivity seems to be involved in age-dependent dystonia in mutant hamsters (Nobrega et al., 1996; Rehders et al., 2000), could in fact be secondary to ontogenetic disturbances of GABAergic inhibition (Richter and Löscher, 1998). Hence, moderate decreases of GABA levels and a reduced expression of the GABA synthesizing enzyme were detected in the striatum of mutant hamsters (Löscher and Hörstermann, 1992; Burgunder et al., 1999). In accordance with the hypothesis that idiopathic dystonias are attributable to biochemical dysf unctions within basal ganglia nuclei (Wichmann and DeLong, 1996), previous examinations in mutant hamsters have shown an increased neuronal activity within the striatum (Richter et al., 1998; Gernert et al., 1999a).

In the present study, we examined whether these striatal dysfunctions could be related to abnormalities of aspiny GABAergic interneurons in the whole neostriatum or striatal subregions of the $d t^{s z}$ mutant. GABAergic interneurons, which coexpress the calciumbinding protein parvalbumin, constitute only $3-5 \%$ of the cells in the rodent neostriatum but are the main inhibitory source in the striatum (Kawaguchi et al., 1995). Single parvalbumin-containing $\left(\mathrm{PV}^{+}\right)$ interneurons exert powerful inhibitory control on the activity of projection neurons in the striatum by innervating a large number of neurons (Koos and Tepper, 1999). Staining with PV antibodies can be used to identify these striatal GABAergic interneurons (Cowan et al., 1990; Kawaguchi et al., 1995). The functional relevance of the present results of PV immunohistochemistry was examined by further pharmacological and electrophysiological investigations. 


\section{MATERIALS AND METHODS}

Animals. The present experiments were performed in male and female $d t^{s z}$ mutant Syrian golden hamsters, which were obtained by selective breeding as described in detail previously (Löscher et al., 1989). In mutant hamsters, the motor disturbances are transmitted by a recessive gene (Richter and Löscher, 1998). As in recent examinations (Gernert et al., 1999a; Nobrega et al., 1999), age- and sex-matched nondystonic control hamsters, used in the present study, were obtained by breeding pairs of an outbred line of Syrian hamsters that were provided by a commercial breeder (Central Institute for Laboratory Animal Breeding, Hannover, Germany). All dystonic and control hamsters were born and kept under the same controlled environmental conditions. All experiments were done in compliance with the German Animal Welfare Act.

Induction of dystonic attacks and severity score of dystonia. As reported previously in detail (Richter and Löscher, 1998), motor impairments in $d t^{s z}$ hamsters show several features in common with human primary paroxysmal nonkinesiogenic dystonia (paroxysmal dystonic choreoathetosis), characterized by long-lasting dystonic attacks. In mutant hamsters, dystonic attacks can be reproducibly induced by a triple stimulation technique (Löscher et al., 1989; Richter and Löscher, 1998), i.e., stressful stimuli consisting of (1) taking the animal from its home cage and placing it on a balance, (2) injection of saline (or of muscimol; see Pharmacological examinations), and (3) placement of the animal in a new plastic cage. After this procedure, $d t^{s z}$ hamsters develop a sequence of abnormal movements and postures. Therefore, the severity of dystonia can be rated by following score system (Löscher et al., 1989): stage 1, flat body posture; stage 2, facial contortions, rearing with forelimbs crossing, and disturbed gait with hyperextended forepaws; stage 3, hyperextended hindlimbs so that the animals appear to walk on tiptoes; stage 4, twisting movements and loss of balance; stage 5 , hindlimbs hyperextended caudally; and stage 6 , immobilization in a twisted, hunched posture with hindlimbs and forelimbs tonically extended forward. After reaching the individual maximum stage, the hamsters recover within $2-5 \mathrm{hr}$. The individual maximum stage of dystonia is usually reached within $3 \mathrm{hr}$ after the hamsters were placed in the new cage. In the present study, all animals were examined for the presence of dystonia after weaning at the age of $21 \mathrm{~d}$ by the triple stimulation procedure, including injections of saline. The groups of mutant hamsters and control hamsters, used for immunhistochemical and electrophysiological examinations, were again tested at an age of $30 \mathrm{~d}$ by triple stimulation, i.e., by injections of saline. Thus, the animals used for these experiments were not pretreated with any pharmacological active compounds. Only $d t^{s z}$ hamsters that exhibited at least stage 3 at both days were used for immunhistochemical or electrophysiological studies, respectively. The four groups of mutant hamsters used for pharmacological investigations were repeatedly tested by triple stimulations (injections of saline) every $2-3 \mathrm{~d}$ after weaning until the severity of dystonia and latencies to the different stages were determined to be reproducible. In these hamsters, the effects of muscimol were examined at an age of 33-42 d (see below).

PV immunohistochemistry. As in recent immunhistochemical studies (Nobrega et al., 1999), groups of seven $d t^{s z}$ hamsters and seven age- and sex-matched nondystonic controls were tested at an age of 21 and $30 \mathrm{~d}$ by triple stimulation technique (see above). All mutant hamsters exhibited severe dystonia, whereas no motor impairments were provoked in control animals. At an age of $31 \mathrm{~d}$, both groups were deeply anesthetized with pentobarbital and transcardially perfused with $0.01 \mathrm{M}$ PBS, pH 7.4, followed by $4 \%$ paraformaldehyde-PBS. Brains were post-fixed for $2 \mathrm{~d}$ in $4 \%$ paraformaldehyde-PBS. The brains were then placed in $30 \%$ sucrose-PBS for $3 \mathrm{~d}$ at $4^{\circ} \mathrm{C}$. Thereafter, the brains were cut on a freezing microtome into two series of $40-\mu \mathrm{m}$-thick coronal sections. One series was stained with thionin. For identification of GABAergic interneurons, the other series was incubated in $2 \%$ hydrogen peroxide for $30 \mathrm{~min}$ and rinsed thoroughly in Tris-buffered saline (TBS) before being processed for the immunohistochemical localization of PV-immunoreactive neurons. Sections from mutant hamsters and control animals were processed identically and in parallel. The sections were preincubated in a blocking solution containing normal rabbit serum, bovine serum albumin, and Triton X-100 in TBS for $60 \mathrm{~min}$. Thereafter, the sections were transferred into the primary antibody (monoclonal mouse anti-parvalbumin IgG1 isotype, 1:2000; Sigma, Deisenhofen, Germany) for $20 \mathrm{hr}$ at room temperature. Then, the sections were rinsed in TBS and placed in biotin-labeled secondary antiserum (rabbit anti-mouse IgG, 1:500; Sigma) for $60 \mathrm{~min}$. The sections were then rinsed in TBS and incubated in horseradish peroxidase-labeled streptavidin (1:375; Dako, High Wycombe, UK), followed by the nickel-intensified diaminobenzidine reaction ( $0.05 \%$ 3,3-diaminobenzidine and $0.6 \%$ ammonium nickel sulfate in TBS) in the presence of $0.01 \%$ hydrogen peroxide for $15 \mathrm{~min}$. Finally, the sections were mounted on glass slides and air dried, and $\mathrm{PV}^{+}$cells were analyzed under a microscope.

All PV-labeled neurons in the striatum were counted by an investigator who was unaware of the origin of the sections. The number and density of $\mathrm{PV}^{+}$neurons were determined according to the stereological method described in detail by Saper (1996) and West (1999), using an image analysis system (KS 300; Kontron, Eching, Germany), in the following striatal subregions [distance to interaural zero (A) in $\mathrm{mm}$ according to Knigge and Joseph, 1968]: anterior (A 7.3-A 6.7), posterior (A 3.7-A 2.7), and the middle part (A 6.7-A 3.7), which was further dissected into dorsomedial, dorsolateral, ventromedial, and ventrolateral subregions (see Fig. 1). The $\mathrm{PV}^{+}$interneurons within the left and right striata were determined per section and subregion. For evaluations of the density of $\mathrm{PV}^{+}$cells, the areas were measured and the volume was determined $(1 / 2$ area section $1+$ area $2+$ area $3 \ldots+1 / 2$ area $n-1) \times$ distance.

Significant differences between mutant hamsters and control animals were calculated by the Student's $t$ test $(p<0.05$ was considered significant).

Pharmacological examinations. The effects of muscimol on severity of dystonia were examined in groups of seven to nine dystonic hamsters at an age of 33-42 d. Dystonic attacks were induced by the procedure of triple stimulation, as described above, but instead of saline, muscimol was injected intraperitoneally (injection volume, $5 \mathrm{ml} / \mathrm{kg}$ ) or into the dorsal striatum per microinjections (bilateral $0.5 \mu \mathrm{l}$ per hemisphere). For predrug and postdrug control recordings, the animals received the same volume of vehicle (saline) intraperitoneally or intrastriatally, respectively. Because the individual maximum stage of dystonia (score rating system; see above) is usually reached within $3 \mathrm{hr}$, the hamsters were observed for $3 \mathrm{hr}$ after triple stimulation. During this period, the severity of dystonia, the latencies to the different stages, and the side effects were noticed. The rater of the severity of dystonia was blind to the treatment condition of the animals. Predrug and postdrug control trials were undertaken $2 \mathrm{~d}$ before and $2 \mathrm{~d}$ after drug testing. All control and drug trials were done at the same time of the day between 9:00 and 12:00 A.M.

For bilateral microinjections of muscimol into the dorsal striatum, permanent stainless steel guide cannulas (length, $12.7 \mathrm{~mm}$; inner diameter, 0.4 $\mathrm{mm}$ ) were chronically implanted in groups of seven to nine mutant hamster at an age of 31-33 d, as described previously (Rehders et al., 2000). For this procedure, the anesthetized hamsters (pentobarbital, $60 \mathrm{mg} / \mathrm{kg}$ ) were placed in a stereotaxic frame. In each animal, bilateral guide cannulas were implanted into the striatum according to the following coordinates (relative to bregma, in millimeters), which were experimentally determined according to the method of Paxinos and Watson (1986) in previous experiments (Rehders et al., 2000): anteroposterior, +1.5; lateral, \pm 2.1 ; ventral, -2.4 . The guide cannulas were held in place with anchor screws and dental acrylic cement on the skull surface. Two to $3 \mathrm{~d}$ after surgery, the microinjections into the striatum of unanesthetized hamsters were performed using an injection cannula (length, $13.7 \mathrm{~mm}$; inner diameter, 0.2 $\mathrm{mm}$ ), which was inserted through the guide cannula into the left and right striatum (ventral, -2.7 to bregma). The drug solutions or vehicle (for predrug and postdrug recordings) were bilaterally delivered in a volume of $0.5 \mu \mathrm{l}$ per hemisphere at a rate of $0.1 \mu \mathrm{l} / \mathrm{min}$. The injection cannula was removed $5 \mathrm{~min}$ after the administration. Already during these first $10 \mathrm{~min}$ of injection procedure, the severity of dystonia and behavioral effects were noted.

Three hours after the striatal microinjections, the hamsters were deeply anesthetized with pentobarbital $(100 \mathrm{mg} / \mathrm{kg}$, i.p.) and transcardially perfused with PBS, followed by $4 \%$ phosphate-buffered formaldehyde. Coronal sections $(52 \mu \mathrm{m})$ were Nissl-stained, and the positions of the tip of the guide cannulas were determined according to the stereotaxic atlas of the golden hamster (Knigge and Joseph, 1968). Only animals with correct placement of the guide cannula in the dorsal striatum were considered for final evaluations of striatal drug effects.

The significance of differences in severity of dystonia between control trials (predrug and postdrug) and drug trial in the same group of animals was calculated by the Friedman test and, if there was found a significant difference (at least $p<0.05$ ), the Wilcoxon signed rank test for paired replicates was used post hoc to determine which pairs differed.

Single-unit recordings within the entopeduncular nucleus. The experiments were performed in groups of $15 d t^{s z}$ hamsters and 16 control hamsters at an age of 32-42 d. All animals were examined for the presence of dystonia at the age of 21 and $30 \mathrm{~d}$. Mutant hamsters exhibited dystonic attacks (stage 3 to stage 6), whereas motor impairments were absent in control animals. The spontaneous firing rate of single neurons of the entopeduncular nucleus (EPN), the homolog of internal segment of the globus pallidus in primates, was examined by extracellular single-unit recordings using standard techniques, as described previously (Gernert et al., 1999a,b,c). Initially, the hamsters received methohexital $(55 \mathrm{mg} / \mathrm{kg}$, i.p.; Lilly, Gie $\beta e n$, Germany) combined with the opioid analgesic fentanyl $(0.05 \mathrm{mg} / \mathrm{kg}$, i.p.; Janssen, Neuss, Germany) for anesthesia during surgical preparations, i.e., tracheotomy, vagotomy, and cannulation of the vena jugularis dexter. The hamsters were ventilated with $\mathrm{O}_{2} /$ room air (rate, $60-70 / \mathrm{min}$; tidal volume, $0.8-2 \mathrm{ml}$ ) to maintain an expired $\mathrm{CO}_{2}$ level of $2-3 \%$ as measured by $\mathrm{CO}_{2}$ gas analyzer. After all surgical procedures, a bolus of gallamine $(30 \mathrm{mg} / \mathrm{kg}$, i.p.; Sigma) was given intraperitoneally, and then the hamsters received an infusion of gallamine $\left(15 \mathrm{mg} \cdot \mathrm{kg}^{-1} \cdot \mathrm{hr}^{-1}\right)$ and fentanyl $(0.05$ $\left.\mathrm{mg} \cdot \mathrm{kg}^{-1} \cdot \mathrm{hr}^{-1}\right)$ throughout the recordings. During the experiments, the heart rate and body temperature, maintained at $37^{\circ} \mathrm{C}$ by heat pad, were continuously monitored.

A single-barrel glass microelectrode, filled with horseradish peroxidase in Tris-buffered saline, was lowered through a small burr hole in the skull to the EPN. The stereotaxic coordinates of the EPN, in millimeters relative to bregma according to the method of Paxinos and Watson (1986), were experimentally determined: posterior, 0.4-0.6; lateral, 2.2; ventral, -6.0 . The electrode was slowly lowered under continuous recording of extracellular neural signals until a spontaneously active EPN neuron could be identified. If possible, several neurons per animal were recorded. Standard techniques for amplifying, discriminating, and processing extracellular single-unit action potential were used by means of the DataWave 

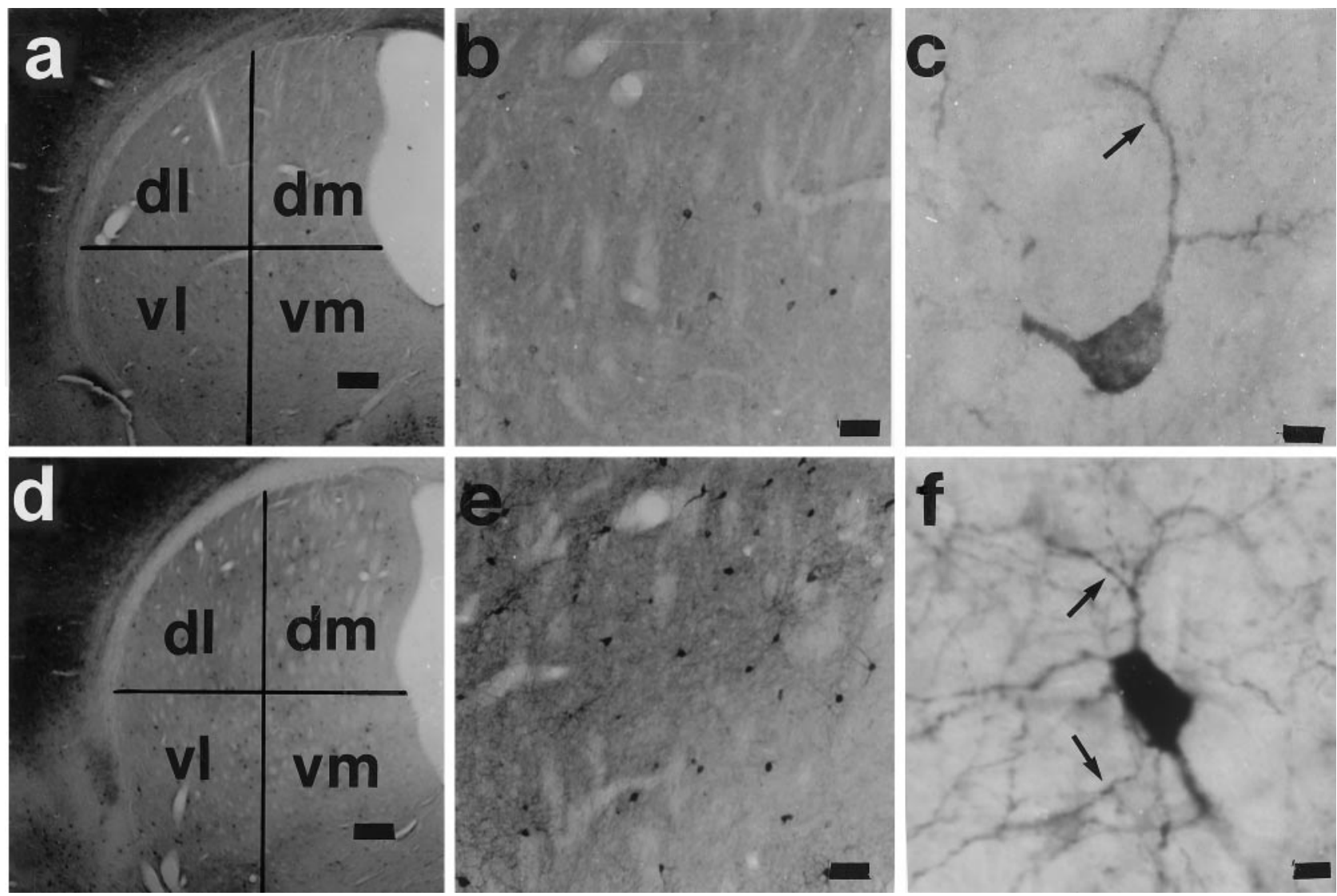

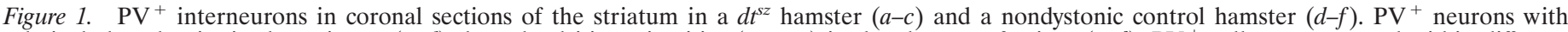

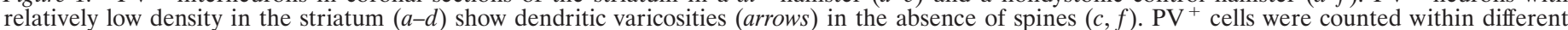

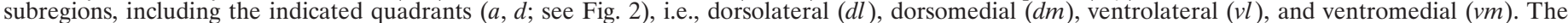

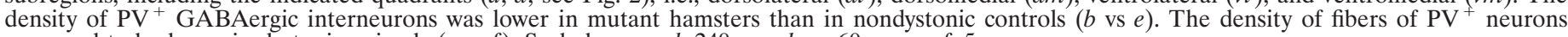
appeared to be lower in dystonic animals ( $c$ vs $f$ ). Scale bars: $a, d, 240 \mu \mathrm{m} ; b, e, 60 \mu \mathrm{m} ; c, f, 5 \mu \mathrm{m}$.

System (WissTech, Spechbach, Germany). After identifying a stable EPN neuron with electrophysiological characteristics of GABAergic neurons, the spontaneous discharge rate was monitored and averaged over $10-15$ min. In both groups, recordings on EPN neurons were started 80 min after the last injection of the short-acting barbiturate methohexital.

At the end of each recording period, the location of the electrode tip was marked for every recorded neuron by microiontophoretical injection of a small amount of horseradish peroxidase, as described previously (Gernert et al., 1999a,b,c). Finally, the hamsters were deeply anesthetized with pentobarbital and transcardially perfused (see above). Then the brains were removed and sectioned, and after staining of horseradish peroxidase the location of recording electrodes could be verified. Only neurons with electrode location in the EPN, 7.1-7.8 mm relative to interaural zero, were used for further evaluation of data. In both groups, most neurons were recorded between 7.2 and $7.6 \mathrm{~mm}$.

The spontaneous discharge rates of EPN neurons were averaged per animal. The statistical significance of the differences between the medians of these averaged activity of the mutant and the control group was calculated using the Mann-Whitney $U$ test and intergroup differences of the means by the $t$ test.

\section{RESULTS}

\section{$\mathrm{PV}^{+}$GABAergic interneurons in striatal subregions}

In normal hamster brains, the distribution of PV-reactive cells (Fig. 1) was similar to the described pattern in rat brains with a relatively low density within the neostriatum (Cowan et al., 1990), allowing to count all striatal $\mathrm{PV}^{+}$neurons. PV-reactive cells in the striatum of $d t^{s z}$ mutant hamsters and nondystonic control hamsters showed the morphological characteristics of aspiny GABAergic interneurons with varicose dendrites (Fig. 1c,f), as described previously for rodents (Cowan et al., 1990; Kawaguchi et al., 1995). By using a stereological counting method in a blinded manner, the number of all PV-reactive interneurons per section was determined. A significant reduction in the number of $\mathrm{PV}^{+}$neurons $(-41 \%, p<0.0001)$ was found within the whole neostriatum of dystonic hamsters compared with age- and sex-matched nondystonic control hamsters. As shown in Figure $2 A$, the number (calculated per region) was significantly lower in all investigated subregions, i.e., in the anterior $(-48 \%)$, dorsomedial $(-31 \%)$, dorsolateral $(-27 \%)$, ventromedial $(-27 \%)$, ventrolateral $(-29 \%)$, and posterior $(-43 \%)$ striatum of mutant hamsters. The number of interneurons did not differ between the left and right striatum in both dystonic and control groups. Compared with control hamsters, the striata were, however, found to be smaller $(-13 \%)$ in dystonic animals. Therefore, the density of $\mathrm{PV}^{+}$GABAergic interneurons was determined, which was reduced by $26 \%$ in the whole striatum of mutant hamsters $(p=0.0006)$. As shown in Figure $2 B$, most marked decreases of the density of $\mathrm{PV}^{+}$interneurons became evident in the anterior $(-44 \%)$ and posterior $(-29 \%)$ striatum of mutant hamsters, but the density was also significantly lower in the middle part, i.e., the dorsomedial $(-21 \%)$, dorsolateral $(-19 \%)$, ventromedial $(-17 \%)$, and ventrolateral $(-21 \%)$ striatum. Furthermore, the density of the fibers of $\mathrm{PV}^{+}$neurons was lower in mutant hamsters than in control animals (Fig. 1c,f). The extent of PV labeling in single neurons was similar in both groups.

\section{Effects of muscimol after striatal and systemic administrations}

In $d t^{s z}$ hamsters, the GABA ${ }_{\triangle}$ receptor agonist muscimol significantly reduced the individual maximum severity of dystonic attacks after systemic (intraperitoneal), as well as after bilateral, striatal microinjections (Fig. 3). Behavioral effects were hyperlocomotion after administration of $1 \mathrm{mg} / \mathrm{kg}$ intraperitoneally and after bilateral striatal injections of $50 \mathrm{ng} / \mathrm{hemisphere}$. At higher doses of 2 $\mathrm{mg} / \mathrm{kg}$ intraperitoneally or $100 \mathrm{ng} /$ hemisphere, muscimol caused moderate sedation and reduced locomotor activity. These adverse 

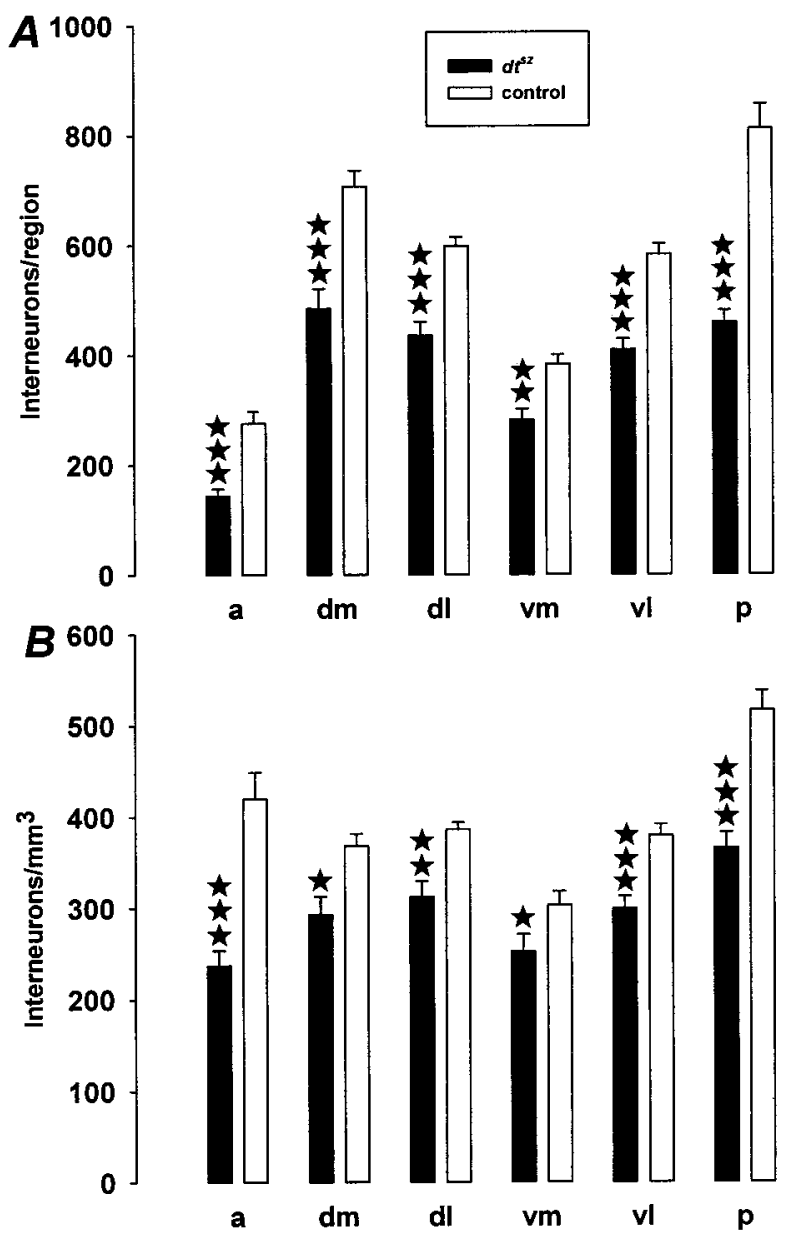

Figure 2. Total number $(A)$ and density $(B)$ of $\mathrm{PV}^{+}$GABAergic interneurons in striatal subregions, i.e., the anterior $(a)$, middle part (see Fig. 1; dorsomedial, $d m$; dorsolateral, $d l$; ventromedial, $v m$; and ventrolateral, $v l$ ), and posterior $(p)$ striatum. The data are shown as means $+\mathrm{SE}$ of the average count of the left and right hemisphere of seven $\mathrm{dt}^{s z}$ and seven control hamsters. Significant differences in the number of interneurons per region and in the density within the subregions are indicated by asterisks $\left({ }^{*} p<0.05 ;{ }^{* *} p<0.001 ; * * * p<0.0001\right)$. The number of interneurons shown in the figure has to be multiplicated $\times 4$, because every fourth section was used for counting.

effects lasted from 10 to 180 min after injection of the different doses and routes of administration.

\section{Neuronal activity in the entopeduncular nucleus}

In vivo extracellular single-unit recordings showed that the average firing rate of entopeduncular neurons in $d t^{s z}$ hamsters was significantly lower compared with nondystonic controls (Fig. 4). The mean \pm SE of the averaged discharge rates per animal were $7.67 \pm$ 1.49 spikes/sec of 30 neurons in 15 mutant hamsters versus $25.14 \pm$ 3.17 spikes/sec of 36 neurons in 16 control hamsters $(p<0.0001)$ (Table 1). The three mutant hamsters with mean discharge rates higher than 10 spikes/sec (Fig. 4) had exhibited less marked dystonia (stage 3 ) than hamsters with lower discharge rates. The reduced activity was found in both anterior and caudal entopeduncular neurons of dystonic animals (data not shown). All recorded neurons in the entopeduncular nucleus of dystonic hamsters and control animals exhibited the electrophysiological characteristics of GABAergic neurons of basal ganglia output structures, as described previously (Guyenet and Aghajanian, 1978; Gernert et al., 1999b; Ruskin et al., 1999), i.e., smooth, sharp, biphasic action potentials with a duration of $0.6-1.5 \mathrm{msec}$ (Fig. 5).

\section{DISCUSSION}

Idiopathic dystonias have been reported to occur in the absence of any lesions that can be defined by either standard postmortem

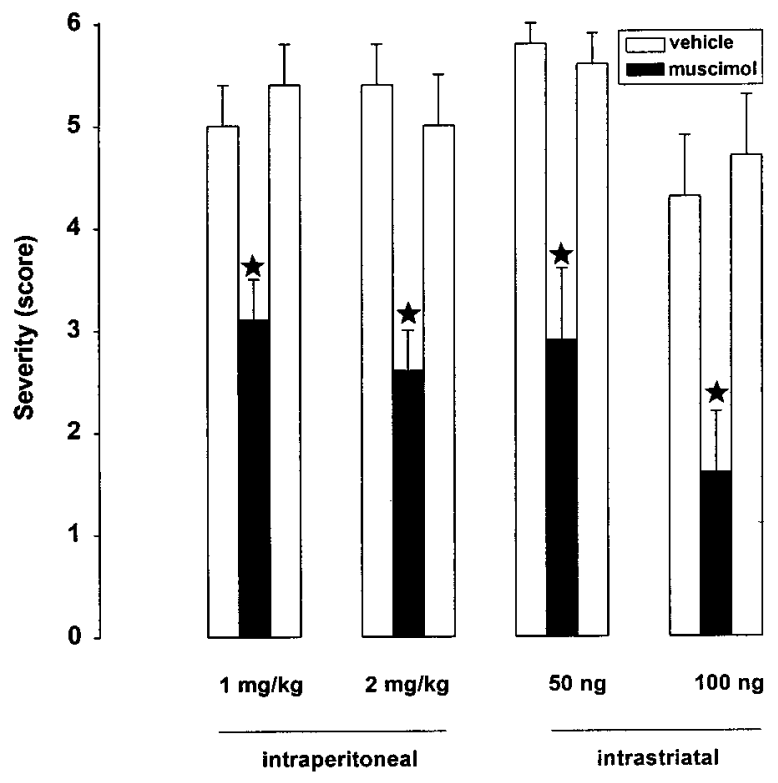

Figure 3. Effect of muscimol on severity of dystonia in mutant hamsters after systemic administration of 1 and $2 \mathrm{mg} / \mathrm{kg}$ (intraperitoneally) and bilateral striatal injections (50 and $100 \mathrm{ng} / \mathrm{hemisphere}$ ). The figure shows the average of the maximum individual severity scores of dystonia, which were reached $3 \mathrm{hr}$ after the induction of dystonic attacks by stressful stimuli, i.e., injections of muscimol or for control recordings of vehicle (saline). Control recordings were taken $2 \mathrm{~d}$ before (predrug control) and $2 \mathrm{~d}$ after (postdrug control) the drug trial. Data are shown as means + SE of seven (100 ng intrastriatal) or nine $(1$ and $2 \mathrm{mg} / \mathrm{kg}, 50 \mathrm{ng})$ dystonic hamsters. Significant differences are indicated by asterisks $\left({ }^{*} p<0.01\right)$.

\section{Single unit activity in EPN}

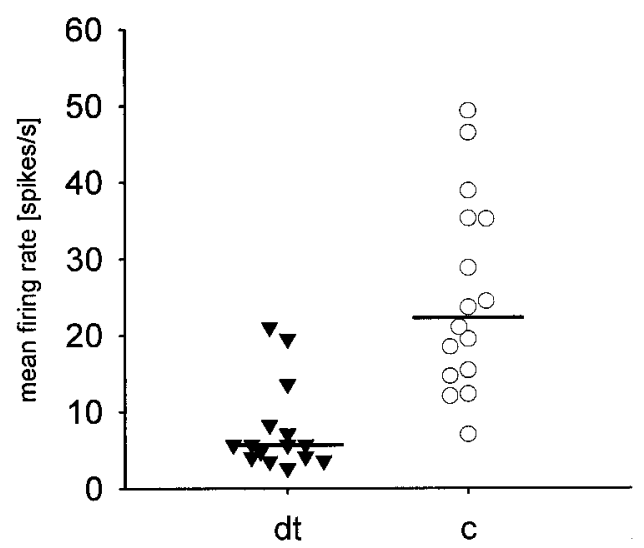

Figure 4. Spontaneous discharge rates of entopeduncular neurons recorded extracellularly and averaged over $10-15$ min recording time from dystonic $(d t)$ animals and nondystonic control hamsters $(c)$. The symbols represent the average discharge rate of one to four neurons per animal. Medians are shown as a horizontal bar. Between the group of 15 dystonic hamsters and 16 control hamsters, significant differences became evident $(p<0.0001)$.

pathological investigations or in vivo imaging (McGeer and McGeer, 1995). However, those examinations do not exclude changes of specific types of neurons. Thus, similar to idiopathic dystonias in humans, no pathomorphological changes could be detected by neuropathological standard techniques within the CNS of $d t^{s z}$ hamsters (Wahnschaffe et al., 1990). Here, we demonstrate for the first time a deficiency of striatal $\mathrm{PV}^{+}$GABAergic interneurons in a type of idiopathic inherited dyskinesia with paroxysmal dystonia. Although hyperkinetic movement disorders, such as symptomatic dystonia and choreoathetosis, are often associated with striatal lesions (Bhatia and Marsden, 1994; Craver et al., 1996), $\mathrm{PV}^{+}$ interneurons have not yet been examined in autopsy material from 


\begin{tabular}{|c|c|c|c|c|}
\hline Region & $d t^{\mathrm{sz}}$ & Control & $\%$ & $p$ \\
\hline EPN & $\begin{array}{c}7.7 \pm 1.5 \\
(30 / 15)\end{array}$ & $\begin{array}{c}25.1 \pm 3.2 \\
\quad(36 / 16)\end{array}$ & -69.5 & $<0.0001$ \\
\hline $\mathrm{CPu}(\mathrm{dm})^{a}$ & $\begin{array}{c}2.4 \pm 0.2 \\
(13 / 8)\end{array}$ & $\begin{array}{c}1.0 \pm 0.1 \\
(15 / 10)\end{array}$ & +58.3 & $<0.01$ \\
\hline $\mathrm{SNr}^{b}$ & $\begin{array}{c}20.0 \pm 2.0 \\
(23 / 12)\end{array}$ & $\begin{array}{c}20.0 \pm 2.0 \\
\quad(17 / 13)\end{array}$ & 0.0 & $>0.05$ \\
\hline $\mathrm{GP}^{c}$ & $\begin{array}{c}28.3 \pm 5.8 \\
(11 / 9)\end{array}$ & $\begin{array}{c}20.2 \pm 2.2 \\
\quad(18 / 13)\end{array}$ & +40.0 & $>0.05$ \\
\hline
\end{tabular}

The firing rates of single recorded neurons examined in different basal ganglia nuclei by using the same methods as in the present study were averaged over 10-15 min recording time and were then averaged per animal. The data are shown as means \pm SE (spikes per second) of the averaged discharge rates of the different animal groups (number of neurons per number of animals). Relative increases $(+\%)$ or decreases $(-\%)$ of discharge rates found in dystonic hamsters compared with nondystonic control animals are indicated. EPN, Entopeduncular nucleus; $\mathrm{CPu}(\mathrm{dm})$, dorsomedial striatum (Gernert et al., 1999a) ${ }^{a}$; SNr, substantial nigra pars reticulata (Gernert et al., 1999b) $)^{b}$; GP, globus pallidus (Gernert et al., 1999c) ${ }^{c}$.
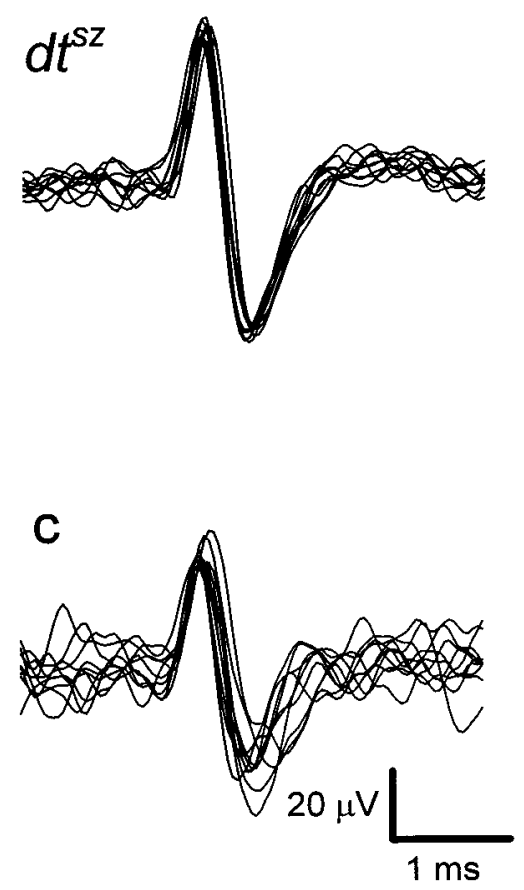

Figure 5. Superimposed spikes $(n=10)$ of two spontaneously active, characteristic neurons from the entopeduncular nucleus of a dystonic $\left(d t^{s z}\right)$ hamster and a nondystonic control $(c)$ hamster. The recorded neurons showed a biphasic positive-negative waveform.

patients with symptomatic or idiopathic dystonias. The occurrence of dystonias may be dependent on the relation between losses of interneurons and projection neurons in the striatum, which could explain that striatal lesions do not always cause (symptomatic) dystonias (McGeer and McGeer, 1995). Despite their relatively low number, $\mathrm{PV}^{+}$interneurons provide the main inhibitory GABAergic control in the striatum (Kawaguchi et al., 1995; Koos and Tepper, 1999). The present finding of an inborn reduction of $\mathrm{PV}^{+}$ interneurons in mutant hamsters indicates that GABAergic interneurons deserve attention in human idiopathic dystonias, particularly in types of dystonia in which GABA-potentiating drugs exert beneficial effects (Fahn, 1995). The detection of structural defects can be helpful for the development of more effective rational drug therapies or surgical treatments of dystonia, e.g., in cases of a loss of $\mathrm{PV}^{+}$interneuron striatal implantations of GABA-producing neurons (Nakao and Itakura, 2000).

Recent hypotheses of the pathophysiology of dystonias mainly focus on the dopaminergic system (Todd and Perlmutter, 1998). Indeed, nigrostriatal dopaminergic dysfunction is possibly the underlying mechanism in some types of hereditary dystonia, such as dopa-responsive dystonia (Todd and Perlmutter, 1998). On the other hand, dopaminergic overactivity suggested by the beneficial effects gained by using neuroleptics in other types of dystonia and dyskinesias (Fahn, 1995) could be secondary to GABAergic disinhibition. In the striatum, GABA obviously inhibits the dopamine release (Gruen et al., 1992), so that a reduction of striatal GABAergic interneurons, as found in mutant hamsters, may result in enhanced dopaminergic activity. In $d t^{s z}$ hamsters, immunhistochemical examinations of the number of dopaminergic neurons in the substantia nigra and ventral tegmental area (Nobrega et al., 1999) and neurochemical studies did not reveal any changes of the dopaminergic system (Löscher et al., 1994; Burgunder et al., 1999; Nobrega et al., 1999). Otherwise, beneficial effects of dopamine receptor antagonists after systemic and striatal injections (Rehders et al., 2000) and decreased dopamine $\mathrm{D}_{1}$ and $\mathrm{D}_{2}$ receptor binding in the dorsal striatum, possibly attributable to downregulation (Nobrega et al., 1996), suggested that striatal dopaminergic overactivity is involved in the manifestation of dystonic attacks in mutant hamsters. Apart from dopaminergic effects on spiny projection neurons (see below), dopamine can decrease via $\mathrm{D}_{2}$ receptors the rate of GABA synthesis and the inhibitory control of striatal $\mathrm{PV}^{+}$interneurons (Hossain and Weiner, 1995; Kawaguchi et al., 1995). Assuming that the deficit of $\mathrm{PV}^{+}$interneurons represents the primary defect in the hamster model, dopamine $\mathrm{D}_{2}$ receptor agonists should aggravate dystonia. In fact, pharmacological stimulation of striatal dopamine $\mathrm{D}_{2}$ receptors by quinpirole aggravated dystonia in mutant hamsters (Rehders et al., 2000). Stress and caffeine, which precipitate dystonic attacks in $d t^{s z}$ hamsters and patients with paroxysmal dystonic choreoathetosis (Demirkiran and Jankovic, 1995; Richter and Löscher, 1998), are known to enhance dopamine levels in the striatum (Abercrombie et al., 1989; Fredholm, 1995). Thereby, enhanced $\mathrm{D}_{2}$ receptor activation on GABAergic interneurons may give rise to a further disinhibition of the striatal dopamine release, leading to imbalances between the direct (striatonigral) and indirect (striatopallidal) projections to the basal ganglia output structures (see below). Thus, the permanent reduction of $\mathrm{PV}^{+}$interneurons does not lead to dystonia by itself, but the decreased striatal inhibition of stressinduced dopamine release may result in the manifestation of a dystonic attack. Because the present data indicate that the striatal dopaminergic overactivity in the genetic animal model is probably attributable to a deficit of GABAergic interneurons, examinations of the pathogenesis in human dystonia should not be restricted to the dopaminergic system.

Apart from striatal dopaminergic overactivity, reduced presynaptic and postsynaptic GABAergic inhibition by deficiency of $\mathrm{PV}^{+}$ interneurons in the striatum can explain a series of other recent pharmacological, neurochemical, and electrophysiological findings in the animal model of paroxysmal dystonia (Richter and Löscher, 1998), e.g., moderate, but significantly decreased levels of GABA (Löscher and Hörstermann, 1992) and of the GABA-synthesizing enzyme glutamic acid decarboxylase (Burgunder et al., 1999) in the striatum. There is evidence for the absence of collateral inhibition of $\mathrm{PV}^{+}$GABAergic interneurons by the spiny projection neurons. Interneurons seem to communicate through electrotonic coupling (Koos and Tepper, 1999; Martina et al., 2000). A reduced number and density of these interneurons in mutant hamsters is likely to cause a disturbance of the interneuronal network. Recent quantitative electroencephalographic depth electrode recordings from the striatum of mutant hamsters excluded epileptogenic changes but indicated altered neuronal synchronization (Gernert et al., 1998). Previous findings of enhanced benzodiazepine binding in the striatum of $d t^{s z}$ hamsters was interpreted as an upregulation of $\mathrm{GABA}_{\mathrm{A}}$ receptors (Pratt et al., 1995). This suggestion is clearly 
supported by the present immunhistochemical data, as well as by the marked beneficial effects of the $\mathrm{GABA}_{\mathrm{A}}$ receptor agonist muscimol after striatal injections. The comparable antidystonic effects after systemic and intrastriatal administrations of muscimol clearly indicate that striatal GABAergic disinhibition is functionally relevant for dystonic and choreoathetotic movements.

The present single-unit recordings in the hamster model demonstrated dramatically decreased mean discharge rates of neurons of the EPN, which is in line with the current concept that dystonia in humans is related to lowered discharge rates of pallidothalamic neurons (Wichmann and DeLong, 1996; Vitek et al., 1998), i.e., a reduced activity of GABAergic neurons in the medial segment of the globus pallidus (the entopeduncular nucleus in rodents). This output structure of the basal ganglia receives major GABAergic afferents via the direct pathway, i.e., the monosynaptic striatonigral/striatoentopeduncular projection (Parent and Hazrati, 1995; Chesselet and Delfs, 1996). Therefore, lowered EPN activity is probably the consequence of the deficit of striatal $\mathrm{PV}^{+}$interneurons, which, because of the recently demonstrated overactivity of striatal spiny GABAergic projection neurons in dystonic hamsters (Gernert et al., 1999a) (Table 1), causes an increased inhibition of EPN neurons. The present data provide the first direct evidence for a reduced basal ganglia output in inherited paroxysmal dystonia. Because this finding became evident in mutant hamsters in the absence of dystonic attacks, it can be concluded that the lowered EPN activity is not secondary to the motor disturbances.

Similar to these data, dyskinesias provoked by chronic treatment with dopamine receptor agonists in parkinsonian monkeys, considered as an animal model of iatrogenic dystonia, have been suggested to be attributable to underactivity of the medial globus pallidus (Mitchell et al., 1990; Crossman and Brotchie, 1998). Increased 2-deoxyglucose uptake in this basal ganglia output structure of these monkeys, which exhibited dystonia and chorea, indicated an overactivity of the direct pathway (Crossman and Brotchie, 1998). In the hamster model, recent single-unit recordings (Table 1) have shown moderate alterations of the pattern of neuronal activity in the globus pallidus (e.g., the lateral segment of the globus pallidus in primates), but no changes of the basal discharge rates became evident in this nucleus (Gernert et al., 1999c) or in the substantia nigra pars reticulata (SNr) (Gernert et al., 1999b). Thus, at least in the absence of dystonic attacks, there is no evidence of disturbed activity within the indirect striatal projections via the globus pallidus and subthalamic nucleus to the output nuclei, i.e., the EPN and SNr. During stress-induced dystonic attacks, however, striatal dopaminergic overactivity, as discussed above, is probably caused by the deficiency of $\mathrm{PV}^{+}$interneurons and may lead via activation of $D_{1}$ receptors to a further overactivity of the direct pathway and via stimulation of postsynaptic $\mathrm{D}_{2}$ receptors, thought to be predominantly located on striatopallidal projection neurons (Gerfen, 1992), to a reduced inhibition of the globus pallidus. In accordance with the hypothesis for hyperkinetic disorders (Wichmann and DeLong, 1996), the consequence in the basal ganglia output nuclei of the additional disturbance in the indirect pathway would be a further inhibition via the globus pallidus and a reduced excitation via the subthalamic nucleus (Parent and Hazrati, 1995; Chesselet and Delfs, 1996). As indicated by recent studies, the entopeduncular inhibition of thalamic nuclei and the lateral habenula would be thereby decreased (Ebert et al., 1996; Richter et al., 1998).

The present finding of reduced striatal GABAergic interneurons and decreased neuronal activity in the entopeduncular nucleus in $d t^{s z}$ hamsters supports the hypothesis that dystonic and choreoathetotic movement disorders are attributable to basal ganglia dysfunctions in humans (Wichmann and DeLong, 1996). Changes in other regions of the motor system, such as thalamic nuclei and the red nucleus, shown by recent neurochemical and 2-deoxyglucose uptake studies in mutant hamsters (Richter and Löscher, 1998; Richter et al., 1998), are probably secondary to the here demonstrated mechanisms. The $d t^{s z}$ hamster represents an unique rodent model in which inborn dystonic movements are related to basal ganglia dysfunctions.

As recently suggested by Koos and Tepper (1999), the present findings in genetically dystonic hamsters demonstrate that examinations of striatal $\mathrm{PV}^{+}$GABAergic interneurons can open new possibilities for understanding pathological processes involving the basal ganglia. Apart from dystonia and choreoathetosis, this structural defect, obviously causing abnormal basal ganglia output, may also be important in other hyperkinetic disorders.

\section{REFERENCES}

Abercrombie ED, Keefe KA, Difrischia DF, Zigmond MJ (1989) Differential effects of stress on in vivo dopamine release in striatum, nucleus accumbens and medial frontal cortex. J Neurochem 52:1655-1658.

Bhatia KP, Marsden CD (1994) The behavioural and motor consequences of focal lesions of the basal ganglia in man. Brain 117:859-876.

Burgunder J-M, Richter A, Löscher W (1999) Expression of cholecystokinin, somatostatin, thyrotropin-releasing hormone, glutamic acid decarboxylase and tyrosine hydroxylase genes in the central nervous motor systems of the genetically dystonic hamster. Exp Brain Res 129:114-120.

Chesselet M-F, Delfs JM (1996) Basal ganglia and movement disorders: an update. Trends Neurosci 19:417-422.

Cowan RL, Wilson CJ, Emson PC, Heizmann CW (1990) Parvalbumincontaining GABAergic interneurons in the rat neostriatum. J Comp Neurol 302:197-205.

Craver RD, Duncan MC, Nelson JS (1996) Familial dystonia and choreoathetosis in three generations associated with bilateral striatal necrosis. J Child Neurol 11:185-188.

Crossman AR, Brotchie JM (1998) Pathophysiology of dystonia. In: Advances in neurology, Vol 78, Dystonia 3 (Fahn S, Marsden CD, DeLong MR, eds), pp 19-25. New York: Lippincott-Raven.

Demirkiran M, Jankovic J (1995) Paroxysmal diskinesias: clinical features and classification. Ann Neurol 38:571-579.

Ebert U, Gernert M, Löscher W, Richter A (1996) Abnormal c-fos expression in the lateral habenula during dystonic attacks in a hamster model of idiopathic dystonia. Brain Res 728:125-129.

Fahn S (1995) Medical treatment of dystonia. In: Handbook of dystonia (Tsui JKC, Calne CB, eds), pp 317-328. New York: Dekker.

Fahn S, Bressman SB, Marsden CD (1998) Classification of dystonia. In: Advances in neurology, Vol 78, Dystonia 3 (Fahn S, Marsden CD, DeLong MR, eds), pp 1-10. New York: Lippincott-Raven.

Fredholm BB (1995) Adenosine, adenosine receptors and the actions of caffeine. Pharmacol Toxicol 76:93-101.

Gerfen CR (1992) The neostriatal mosaic: multiple levels of compartimental organization. Trends Neurosci 15:133-139.

Gernert M, Richter A, Rundfeldt C, Löscher W (1998) Quantitative EEG analysis of depth electrode recordings from several brain regions of mutant hamsters with paroxysmal dystonia discloses frequency changes in the basal ganglia. Mov Disord 13:509-521.

Gernert M, Richter A, Löscher W (1999a) Alterations in spontaneous single unit activity of striatal subdivisions during ontogenesis in mutant dystonic hamsters. Brain Res 821:277-285.

Gernert M, Richter A, Löscher W (1999b) Subconvulsive dose of pentylentetrazole increases the firing rate of substantia nigra pars reticulata neurons in dystonic but not in nondystonic hamsters. Synapse 33:259-267.

Gernert M, Richter A, Löscher W (1999c) In vivo extracellular electrophysiology of pallidal neurons in dystonic and nondystonic hamsters. J Neurosci Res 57:894-905.

Gruen RJ, Friedhoff AJ, Coale A, Moghaddam B (1992) Tonic inhibition of striatal dopamine transmission: effects of benzodiazepine and $\mathrm{GABA}_{\mathrm{A}}$ receptor antagonists on extracellular dopamine levels. Brain Res 599:51-56.

Guyenet PG, Aghajanian GK (1978) Antidromic identification of dopaminergic and other output neurons of the rat substantia nigra. Brain Res 150:69-84.

Hossain MA, Weiner N (1995) Interactions of dopaminergic and GABAergic neurotransmission: impact of 6-hydroxydopamine lesions into the substantia nigra of rats. J Pharmacol Exp Ther 275:237-244.

Kawaguchi Y, Wilson CJ, Augood SJ, Emson PC (1995) Striatal interneurons: chemical, physiological and morphological characterization. Trends Neurosci 18:527-535.

Knigge KM, Joseph SA (1968) A stereotaxic atlas of the brain of golden hamster. In: The golden hamster: its biology and use in medical research (Hoffman RA, Robinson PF, Magalhaes H, eds), pp 284-319. Ames, IA: Iowa State University.

Koos T, Tepper JM (1999) Inhibitory control of neostriatal projection neurons by GABAergic interneurons. Nat Neurosci 2:467-472.

Löscher W, Hörstermann D (1992) Abnormalities in amino acid neurotransmitters in discrete brain regions of genetically dystonic hamsters. J Neurochem 59:689-694.

Löscher W, Annies R, Richter A (1994) Marked regional disturbances in brain metabolism of monoaminergic neurotransmitters in the genetically dystonic hamster. Brain Res 658:199-208.

Löscher W, Fisher Jr JE, Schmidt D, Fredow G, Hönack D, Iturrian WB 
(1989) The sz mutant hamster: a genetic model of epilepsy or of paroxysmal dystonia? Mov Disord 4:219-232.

Martina M, Vida I, Jonas P (2000) Distal initiation and active propagation of action potentials in interneuron dendrites. Science 287:295-300.

McGeer EG, McGeer PL (1995) Pathology of dystonia. In: Handbook of dystonia (Tsui JKC, Calne CB, eds), pp 77-102. New York: Dekker.

Mitchell IJ, Luquin R, Boyce CE, Robertson RG, Sambrook MA, Crossman AR (1990) Neural mechanisms of dystonia: evidence from a 2-deoxyglucose uptake study in a primate model of dopamine agonistinduced dystonia. Mov Disord 5:49-54.

Nakao N, Itakura T (2000) Fetal tissue transplants in animal models of Huntington's disease: the effects on damaged neuronal circuitry and behavioral deficits. Prog Neurol 61:313-338.

Nobrega JN, Richter A, Tozman N, Jiwa D, Löscher W (1996) Quantitative autoradiography reveals regionally selective changes in dopamine $\mathrm{D}_{1}$ and $\mathrm{D}_{2}$ receptor binding in the genetically dystonic hamster. Neuroscience 71:927-936.

Nobrega JN, Gernert M, Löscher W, Raymond R, Belej T, Richter A (1999) Tyrosine hydroxylase immunreactivity and [3H]W IN 35,428 binding to the dopamine transporter in a hamster model of idiopathic paroxysmal dystonia. Neuroscience 92:211-217.

Parent A, Hazrati L-N (1995) Functional anatomy of the basal ganglia. I. The cortico-basal ganglia-thalamo-cortical loop. Brain Res Rev 20:91-127.

Paxinos G, Watson C (1986) Brain in stereotaxic coordinates. Sydney: Academic.

Pratt DG, Möhler H, Richter A, Löscher W (1995) Regionally selective and age-dependent alterations in benzodiazepine receptor binding in the genetically dystonic hamsters. J Neurochem 64:2153-2158.

Rehders JH, Löscher W, Richter A (2000) Evidence for striatal dopami- nergic overactivity in paroxysmal dystonia indicated by microinjections in a genetic rodent model. Neuroscience 97:267-277.

Richter A, Löscher W (1998) Pathophysiology of idiopathic dystonia: findings from genetic animal models. Prog Neurobiol 54:633-677.

Richter A, Brotchie JM, Crossman AR, Löscher W (1998) $\left[{ }^{3} \mathrm{H}\right]-2$ Deoxyglucose uptake study in mutant dystonic hamsters: abnormalities in discrete brain regions of the motor system. Mov Disord 13:718-725.

Ruskin DN, Bergstrom DA, Kaneoke Y, Patel BN, Twery MJ, Walters JR (1999) Multisecond oscillations in firing rate in the basal ganglia: robust modulation by dopamine receptor activation and anesthesia. J Neurophysiol 81:2046-2055.

Saper CB (1996) Any way you cut it: a new journal policy for the use of unbiased counting methods. J Comp Neurol 30:24-30.

Spinella GM, Sheridan PH (1994) Research opportunities in dystonia. Neurology 44:1177-1179.

Todd RD, Perlmutter JS (1998) Mutational and biochemical analysis of dopamine in dystonia. Mol Neurobiol 16:135-147.

Vitek JL, Zhang J, Evatt M, Mewes K, DeLong MR, Hashimoto T, Triche S, Bahay RAE (1998) GPi pallidotomy for dystonia: clinical outcome and neuronal activity. In: Advances in neurology, Vol 78, Dystonia 3 (Fahn S, Marsden CD, DeLong MR, eds), pp 211-219. New York: Lippincott-Raven.

Wahnschaffe U, Fredow G, Heintz P, Löscher W (1990) Neuropathological studies in a mutant hamster model of paroxysmal dystonia. Mov Disord 5:286-293.

West MJ (1999) Stereological methods for estimating the total number of neurons and synapses: issues of precision and bias. Trends Neurosci 22:51-61.

Wichmann T, DeLong MR (1996) Functional and pathophysiological models of the basal ganglia. Curr Opin Neurobiol 6:751-758. 